\title{
Protocol for a mixed methods exploratory investigation into the role and contribution of the healthcare assistant in out-of-hours palliative care
}

Felicity Hasson ${ }^{1 *}$, Sonja Mcllfatrick ${ }^{1}$, Sheila Payne ${ }^{2}$, Paul Slater ${ }^{3}$, Dori-Anne Finlay ${ }^{3}$, Tracey McConnell ${ }^{4}$ and Anne Fee ${ }^{1}$ (D)

\begin{abstract}
Background: Most people spend their last year of life at home, with many wishing to die there, but patients may need access to care after hours. Out-of-hours palliative care is delivered by multi-disciplinary teams including Health Care Assistants (HCA). However, little is known about the role, contribution and impact Health Care Assistants have on out-of-hours palliative care services. The aim of this study is to examine the Health Care Assistant role, contribution and impact on service delivery and patient care in out-of-hours community palliative care provided by hospice organisations.
\end{abstract}

Methods and analysis: A mixed methods exploratory study consisting of four phases. Phase one involves a scoping review to systematically map and identify gaps in policy and literature on the HCA role in out-of-hours palliative care. In phase two, all United Kingdom hospices will be invited to participate in an online census to enable the development of a typology of out-of-hours services and the contribution of the Health Care Assistant. During phase three organisational case studies representing different service types will collect information from Health Care Assistants, patients, caregivers and service managers to gather qualitative and quantitative data about out-of-hours service provision and the Health Care Assistant role. Finally, phase four will synthesize and refine results through online focus groups.

Ethics and dissemination: Ethical approval has been obtained for phase two through Ulster University Research Governance Filter Committee, Nursing and Health Research. Findings will be disseminated through practitioner and/or research journals, conferences, and social media.

Keywords: Health care assistant, Out-of-hours care, After hours, Palliative care, Mixed methods, Hospice

\footnotetext{
* Correspondence: f.hasson@ulster.ac.uk

1 Institute of Nursing and Health Research, School of Nursing, Ulster University, Shore Road, Newtownabbey BT37 OQB, Northern Ireland Full list of author information is available at the end of the article
} 


\section{Strengths and limitations of this study}

- This exploratory study uses mixed methods to gather data from multiple perspectives.

- For each out-of-hours service typology, we will develop an in-depth organisational case study to create an understanding of the service, the professionals involved and the role the Health Care Assistant plays.

- Limitations include the single point in time data collection, with data only drawn based on United Kingdom out-of-hours community service models.

- A further limitation is the study is observational rather than interventional.

\section{Background}

Most of the last year of a person's life is spent at home, no matter where the patient eventually dies $[1,2]$. Despite careful planning, unexpected deterioration may occur leading patients and caregivers to access out-ofhours care $[3,4]$. In the United Kingdom (UK), out-ofhours $(\mathrm{OOH})$ care refers to care provided between 18: 30-08:00 on weekdays and throughout the weekends [5]. A recent exercise examining patient priorities demonstrated that $\mathrm{OOH}$ palliative care services were integral to the care of patients at end-of-life [6]. In fact, it has been estimated that $30 \%$ of palliative care patients have accessed $\mathrm{OOH}$ services in the last days of life [7]. However, research in this area has been minimal [8] despite reports of patient safety concerns relating to medication, access to timely care, clinical information and skills and confidence of the $\mathrm{OOH}$ team [5].

Multi-disciplinary teams comprising GPs, District Nurses, Specialist Palliative Care Nurses and Health Care Assistants (HCAs), all with variable training in end-of-life care, have a vital role to play in delivering $\mathrm{OOH}$ care. Even though HCAs (also known as nursing auxiliaries and support workers) are not regulated nor subject to any formal national training standards, they are key in providing home-based palliative care [9-11]. Evidence suggests HCAs play a critical role in the provision of chronic and end of life care [12-16] providing most of the direct care [15], and are often the first to recognise and alert professionals to patient changes $[17,18]$. In the home it has been suggested that HCAs often act as a go-between with the caregiver and healthcare professional, providing support and guidance to caregivers and patients on what to expect, and a reassuring presence up to, and at the point of death [12, 19]. However, research indicates that many HCAs feel under-prepared to deliver chronic and palliative care $[20,21]$.

The contribution and impact of HCAs on hospice $\mathrm{OOH}$ service models remains largely un-reported in the literature, even though the roles of other $\mathrm{OOH}$ palliative team members have been previously examined [4, 22-24]. HCAs are rarely recognised as an integral palliative care team member [20, 25, 26], however, evidence suggests that HCAs are an extremely valuable workforce who make a vital and significant contribution to $\mathrm{OOH}$ palliative care $[12,14,16]$. Thus, a clearer understanding of the HCA role in $\mathrm{OOH}$ palliative care provision is crucial to potentially improve effectiveness of multi-disciplinary team working within $\mathrm{OOH}$ palliative care. Furthermore, developing insight to the range of $\mathrm{OOH}$ community-based service typologies being offered across the UK, and the role of the HCA in each service model may also help to identify strategies to enable patients to remain and die at home.

The current COVID-19 pandemic has resulted in greater pressures than ever before on health and social care practitioners. The pandemic has also resulted in unprecedented restrictions in research data collection within health and social care in order to limit transmission of the virus and also to prioritise resources. Consequently, researchers have had to adapt to ensure that data collection adheres to both methodological and ethical considerations. Therefore, the methods of data collection in the present study have been adapted to take into account current restrictions.

\section{Methods and analysis}

Mixed methods design incorporating both qualitative and quantitative methods will be used as it provides a useful approach when studying real life, contextual situations [27]. Explanatory sequential design is described as "starting by collecting and analysing quantitative data, and then collecting and analyzing qualitative data in a second phase; and finally link the phases by using the quantitative findings to form the qualitative research questions, sampling, and data collection" [27] (p.71). Although an explanatory sequential design will be adopted as the primary design, there will also be elements of exploration in order to gain insight into any inconsistencies [28, 29].

As the aim is to provide an in-depth understanding of the $\mathrm{HCA}$ role in $\mathrm{OOH}$ palliative care, the qualitative data will take priority. A pragmatic paradigm will be applied, intentionally engaging both sets of paradigms and their assumptions, for the research problem under study [30]. Data will be integrated within phases using data transformation and data typology techniques [31]. Full integration will occur when data phases are completed using data matrix [32], following the thread [33]; and merging in a critical interpretation of the synthesis [27]. The study comprises four phases.

\section{Phase 1: scoping review}

The first phase involves a scoping review of policy and related literature to examine and map the types of 
evidence and policy that inform practice in this area as well as identify gaps in knowledge [34]. There is no existing published synthesis on the HCA role in $\mathrm{OOH}$ palliative care that integrates empirical and grey literature to map the body of literature on this complex and heterogeneous topic [35].

In order to enhance rigour and transparency, the sixstage framework for scoping reviews developed by Arskey and O'Malley [36], and Levac et al. [37], will be adopted in order to identify relevant literature. The six stages are:

Stage 1: Identifying the research question - this was developed through consultation with the research team and key stakeholders, for example 'What is the role, responsibilities and contribution of HCAs to palliative and $\mathrm{OOH}$ care?'. Stage 2: Identifying relevant studies this will be achieved by searching several electronic databases (i.e. CINAHL, MEDLINE, EMBASE, PsycINFO), using pre-specified eligibility criteria and supplemented by grey literature searches (e.g., Web of Science Conference proceeding, Grey Literature report, Open Grey). Search terms and strategy will be developed with input from the research team, key stakeholders and an experienced research librarian. Terms will be searched as both keywords in the title and/ or abstract and subject headings (e.g. $\mathrm{MeSH}$ ) as appropriate. English language and date limits of the past 10 years will be applied. Stage 3: Study selection - this will consist of two researchers independently reviewing (a) title and abstract and (b) full texts. In the case of conflicting eligibility, consensus will be reached through discussion with a third investigator. Stage 4: Data collection - this will comprise a generic data extraction template, which will be designed in accordance with the study aims to extract study characteristics. The extraction template will be reviewed by the research team and key stakeholders and pre-tested prior to implementation. Stage 5: Data summary and synthesis of results - this will entail a mapping of the key concepts underpinning the research area, detailing the main sources and types of evidence available. Stage 6: Consultation - this will be undertaken with a patient-partner who will be engaged throughout the study acting as a consultant to ensure the patient voice is captured. In addition, the search approach will be informed throughout by key stakeholders who are subject experts. The scoping study findings will be used to provide a platform for the design of the subsequent phases of the investigation.

\section{Phase 2: Quantitative: survey of UK hospices}

The second phase involves a census of hospices across the UK using a cross sectional survey. This will enable the development of a typology of $\mathrm{OOH}$ services and examination of the HCA workforce characteristics, roles, employment contracts, organisational and regulatory guidelines for service provision within community-based
$\mathrm{OOH}$ care. These findings will establish a national overview of the HCA workforce and their role in community-based $\mathrm{OOH}$ service provision and provide a sampling frame for the selection of 'cases' for phase three.

\section{Population and sample size calculation}

All Directors of Nursing or Community Nursing Services Managers, who have responsibility for hospice workforce staff and expertise in service delivery, based in adult hospices across the UK will be targeted. There were 260 services identified from the Hospice UK Service Directory (retrieved November 2017), and the sample will comprise one member from each service. A power calculation $(95 \%$ confidence level, 5\% confidence interval, 50\% response accuracy, population $n=260$ ) indicates a required sample size of $n=156$ participants (accommodating an anticipated non-response rate for $40 \%$ [38].

\section{Data collection}

An online survey will be developed in line with best practice guidelines $[39,40]$. This will be a selfadministered questionnaire and will facilitate the collection of data in a relatively cost-effective manner within a short time frame.

\section{Questionnaire design \& pilot study}

The survey will be informed by phase one findings and will include forced-choice and short answer (open) responses. The questionnaire will be divided into four main parts. The first will examine the $\mathrm{OOH}$ service typology delivered, models of practice, practice characteristics, accessibility and usage rates. The second section will profile the HCA workforce identifying the number, type, training, and role in the delivery of $\mathrm{OOH}$ care provided for patients receiving hospice care at home. The third part will explore hospice characteristics, size, status, location, and population. The final part will consider how $\mathrm{OOH}$ services and the HCA role has been impacted by COVID-19. Survey findings will be used to identify the variables of case study sites. The instrument will be pilot tested for clarity and face validity by a panel of experts in healthcare workforce, hospice and palliative care.

\section{Survey process}

Each adult hospice organisation will be initially contacted by telephone to identify and confirm the contact details of the most appropriate senior person to contact. An email invitation with a hyperlink to the online survey will then be sent to a senior person (usually Director of Nursing/ Community Nursing Services Manager) with an alternative hyperlink to opt out. Participants will be given a three-week period to complete and return the 
questionnaire online to the research team. To enhance response rates, a reminder email will be issued one week after initial distribution, and if necessary, a final reminder email one week later. The survey will be closed after four weeks. A process of implied consent will be used whereby a returned questionnaire will indicate consent for the data to be examined in the study.

\section{Data analysis}

Data collected from the questionnaire will be cleaned and entered to SPSS (v23). Descriptive statistics will be generated, and normality of distribution assessed. Content analysis will be undertaken of free text replies, to code those answers into a meaningful set of categories that may lend themselves to further quantitative statistical analysis. In addition, to enhance response rates reminder letters and the response rates from the online survey will be calculated according to the Checklist for Reporting Results of Internet E-Surveys (CHERRIES) [41]. Findings from the survey will be used to inform the sampling matrix for the selection of case studies in phase three and areas of interest for data collection.

\section{Phase 3: Qualitative: organisational case studies}

As previously mentioned, phase two will enable an overview of the $\mathrm{OOH}$ service delivery and $\mathrm{HCA}$ role, and will aid in the identification of informants from all the palliative care services for the next round of data collection. The third phase will involve qualitative case studies. It is anticipated that this will result in a better understanding of the topic through an examination of the HCA role, contribution and impact of communitybased $\mathrm{OOH}$ services, and the extent to which they enable people to remain at home.

\section{Population and sample size calculation}

A sampling framework will be used to purposively select up to six organizational case studies [42], of $\mathrm{OOH}$ services from phases one and two. Whilst the sampling criteria will be informed from the findings of phases one and two, the criteria for selection of cases has been further defined as follows: 1) Different configurations of Hospice $\mathrm{OOH}$ community palliative care services such as Rapid Response $\mathrm{OOH}$ Teams, Hospice at Home, Night Nursing Services; 2) The service provision has a multi-disciplinary background (HCAs must be involved in the delivery of care). Each type of model will be represented by at least one case study and $\mathrm{OOH}$ service will constitute a unit of analysis. Maximum variety sampling from phase two (survey) will be used to ensure the selected cases incorporate key variables of interest, for example, utilisation of $\mathrm{HCA}$ role, size of service and geographical location. Selecting cases in this manner will help to provide insight into the nature and context of different configurations of hospice $\mathrm{OOH}$ palliative care services, and together will represent the diverse experiences of key stakeholders.

\section{Data collection}

Based on the process model advocated by Yin [43], the approach will employ a mixed methods design to gain in-depth understanding of the HCA role and contribution to $\mathrm{OOH}$ palliative care across service models. Data collection methods will include interviews and documentary analysis. The primary method of data collection will be semi-structured interviews, conducted through a virtual platform (such as Skype or Zoom), each lasting between 30 and $60 \mathrm{~min}$. As an alternative, telephone interviews will also be offered to suit participants' circumstances. Interviews will be undertaken with patients, caregivers and staff associated with each $\mathrm{OOH}$ hospice community service model including HCAs, generalist, specialist and senior managers to provide a contextual picture of $\mathrm{HCAs}$ role within $\mathrm{OOH}$ services. Interviews with patients and caregivers will explore the contribution of the HCAs in patient care. Interviews with HCAs will explore their training, experience, role and contribution in $\mathrm{OOH}$ care delivery. Interviews with staff associated with $\mathrm{OOH}$ care will examine their perceptions of the contribution and impact of the HCA role in providing $\mathrm{OOH}$ support and the nature of working relationships. Senior managers will be asked to provide information about the overall service, the role of HCAs in providing support, training, and other factors influencing service delivery. Agendas for the interviews will be informed by the aims of the study and phase one and two analyses. All instruments will be piloted at a non-participating hospice. Capturing the experience of services and their organisational context will also be achieved through analysis of site-specific documents. Policy and materials relating to $\mathrm{OOH}$ community service models, the HCA role and policies and structures of working will be reviewed for each hospice. In addition, socio-demographic and epidemiological data on the localities in which the case study sites are situated will also be analysed to provide background contextual information for each case.

\section{Recruitment and informed consent}

Prior to data collection a volunteer principal liaison person [44], knowledgeable about the service, will be identified and given further in-depth information about the study. It is anticipated that this individual will act as a central point of contact for the research team and interview participants. Prior to interviews, this individual will be engaged in order to learn more about the service and its wider setting and to assist with recruitment for interviews. Following this, the research team will conduct individual interviews with participants, patients, 
caregivers, HCAs, other health care professionals (HCP) and senior managers, either via a virtual platform (Skype or Zoom) or telephone.

A purposive sample [45] of patients and caregivers $(n=2-4)$ who meet inclusion criteria will be selected from each hospice site. Patients who are willing to take part in the study will be asked to nominate a family caregiver. Separate interviews will be carried out with the patient and their nominated family caregiver to explore experience of the role and contribution of the HCA. These will be followed up with a purposive sample of HCA $(n=1-3)$ and key members of the OOH multidisciplinary team $(n=3-5)$ such as the GP, District Nurse, Specialist Palliative Care Nurse and/or other members of multidisciplinary team as required (e.g., social work), and will be selected from each hospice site (see criteria below). Senior managers and $\mathrm{OOH}$ service coordinators/managers $(n=2-3)$ will also be interviewed from each site. The sample size for qualitative research cannot be specified precisely in advance and data collection will continue until data saturation occurs. It will be deemed that data saturation has been achieved when no new information has been uncovered [46]. All interviews will take place at a time that is convenient to the participants. Participants' demographic information will also be collected using a brief questionnaire.

Inclusion criteria: case studies

1. Patients must be receiving community based palliative care, over 18 years old, physically and mentally capable of participation (judged by HCP) and willing to provide consent.

2. Caregivers must be over 18 years old, nominated by the patient, physically and mentally capable of participation and willing to provide consent.

3. HCAs must be employed in the delivery of $\mathrm{OOH}$ care to palliative care patients in the community, over 18 years old and willing to provide consent.

4. HCPs must be Generalist or Specialist Palliative Care HCPs and willing to provide consent.

5. Managers must be a senior manager within Hospice with a responsibility for delivery of $\mathrm{OOH}$ service and/or HCA management and willing to provide consent.

\section{Data analysis}

Each interview will be digitally audio recorded (with written consent), transcribed and subject to a framework approach to data analysis to enable comparison to be undertaken across and within cases [47]. In phase three, data will be 'embedded' within several sources (patients, caregivers, and healthcare professionals). Within-case analysis will ensure that a detailed understanding of each case study has been achieved. Cross-case analysis will be undertaken to identify cross-cutting themes common to all cases, and contextual issues to specific to individual cases [44]. Themes and patterns of the secondary data will be analysed and contextual issues will be highlighted.

\section{Phase 4: on-line focus groups Goal}

The final phase comprises on-line focus groups. These focus groups will be undertaken to facilitate reflection and discussion of the study's findings, and will contribute to the development of strategic recommendations relating to the $\mathrm{HCA}$ role in $\mathrm{OOH}$ community palliative care provision.

\section{Population and sample size calculation}

A purposive sample of key stakeholders will be invited to take part (four focus groups comprising 5-8 participants per group). Participants will be initially recruited from key workers and stakeholders $(n=8-10)$ who took part in phase three (case studies) and identified as knowledgeable informants about $\mathrm{HCA}$ role and $\mathrm{OOH}$ community palliative care (i.e. HCAs, senior managers and other health care professionals). In addition, a purposive snowball sample of key stakeholders including, patients (with appropriate support to attend) and family caregiver representatives $(n=6-8)$, service managers $(n=3-4)$ and policy makers $(n=3-4)$ will also be invited.

\section{Data collection}

Focus group participants will be drawn from each UK jurisdiction (N. Ireland, Scotland, Wales, England), to ensure equal representation across the British Isles. It is anticipated that each focus group will last $1-1.5 \mathrm{~h}$, on a date to be agreed with stakeholders. Focus groups will be conducted virtually, using videoconferencing (such as Skype or Zoom).

Given that face-to-face focus groups are 'unique' in their ability to produce insight to a phenomenon through participant interaction [48, 49], it could be argued that the virtual nature of the online environment may restrict the capture of nuanced group dynamics [50]. However, there is also some evidence to suggest that there are few differences in the quality of data generated from face-to-face and virtual environments $[51,52]$.

Over and above the risks associated with face-to-face focus groups such as lack of participation, or one person dominating, [48] there are also risks specifically associated with online focus groups. These include - participants lack of knowledge about the use of technology; unsuitable environments resulting in distractions or interruptions (from colleagues or family); privacy and confidentiality issues.

In the present study several measures will be used to mitigate against such issues. For example, for participants 
who are unsure of the online environment, training and a test call will be offered. Specific information included in the Participant Information Sheet, and Consent Form, such as the importance of securing a private space for the duration of the focus group, may help to appraise participants of the online process and expectations [53]. In addition, participants will be asked, if possible, to wear headphones in order to ensure confidentiality [52].

\section{Data analysis}

Quantitative data will be collected using questionnaires designed to formulate a picture of participants sociodemographic details, experience and attitude towards $\mathrm{HCA}$ in $\mathrm{OOH}$ palliative community care. Questions will contain a mixture of open and Likert scale questions. With permission, focus group discussions will be audio recorded, transcribed and subjected to thematic qualitative analysis [54] to determine the central themes. Issues that stakeholders perceive as important, and the development of strategic recommendations relating to the HCA role in $\mathrm{OOH}$ palliative care provision will be highlighted.

\section{Patient and public involvement}

A patient partner has been engaged throughout the study acting as a consultant to ensure the patient voice is captured.

\section{Ethics and dissemination}

Ethical approval has been obtained for phase two through Ulster University Research Governance Filter Committee, Nursing and Health Research. Ethical approval for the remaining phases will be sought in a sequential manner in line with research governance and ethical requirements. All study participants will receive an information sheet detailing the study background, aim, implications and the ethical aspects. In phase two, participants will be made aware that submission of their questionnaire implies consent. In phase three and four full written informed consent will be required from all participants prior to participation. Ethical principles relating to confidentiality and data handling will be observed. Data from the questionnaires will be anonymous. When reporting the results all identifying features will be removed and interviewees will be identified by a unique code that only the research team can access. All data will be stored, maintained and disposed of according to current data protection legislation [55].

\section{Dissemination plan}

A dissemination strategy informed by Evidence-based Model for the Transfer and Exchange of Research Knowledge (EMTReK) in Palliative Care [56], has been developed. EMTReK provides guidance in knowledge transfer and exchange dissemination plans to multiple stakeholders using a range of dissemination tools. For this study the key stakeholders would include academics, palliative and end of life care providers, commissioning organisations, community nursing service providers, patients, caregivers and the public. A multi-facetted approach will be used in disseminating findings to different stakeholders throughout and at the end of the study.

\section{Written information}

Throughout the study participating hospices in phase three (case studies) will be provided with regular updates to communicate to staff (via newsletters) and the wider community (via social media). The full account of the research findings and a plain English summary for public and patient engagement will be published online and will be available to our research participants. We also aim to publish in several peer reviewed and practice-based journals to reach broad audience coverage. The team will publish articles about the research aims and outcomes, designed for the public, including newsletters, research summaries written in plain English and social media feeds such as blogs.

\section{Oral presentations}

Abstracts for oral presentations will be submitted to international and national research forums such as e the Hospice UK conference and the European Association of Palliative Care Congress. At a managerial level, presentations regarding the implications of the findings to health service organisations will be made to service managers responsible for delivering $\mathrm{OOH}$ community services and management of HCA workforce.

\section{Social media}

We will use social media channels (YouTube, Twitter) via Ulster University and establish a dedicated project Twitter account to update on progress and disseminate the work in accessible and engaging format.

\section{Public}

Dissemination of findings aimed at the public will be facilitated through links with organisations including Marie Curie, National Council of Palliative care and Dying Matters.

\section{Abbreviations}

HCA: Healthcare assistant; OOH: Out-of-hours; PC: Palliative Care

\section{Supplementary Information}

The online version contains supplementary material available at https://doi. org/10.1186/s12912-021-00570-x.

Additional file 1.

Acknowledgements None applicable. 


\section{Authors' contributions}

All the authors, (FH, SMcl, SP, PS, D-AF, TMcC, AF) have made intellectual contributions to the manuscript. FH contributed to the conception and design, and was involved in drafting the manuscript. SMCl and SP have both contributed to the conception and design, and have been involved in drafting the manuscript, revising it critically for intellectual content. D-AF, TMCC and AF have been involved in revising the document critically. All authors have agreed to be personally accountable for the author's own contributions and to ensure that questions related to the accuracy or integrity of any part of the work, even ones in which the author was not personally involved, are appropriately investigated, resolved, and the resolution documented in the literature. All authors have read and approved the final manuscript.

\section{Funding}

This study was funded by Marie Curie Research Grants Programme grant number MCRGS-20171219-8007. Funders had no part in study design, data collection, data analysis or preparation of this manuscript.

\section{Availability of data and materials}

The datasets used and/or analysed during the current study will be available from the corresponding author on reasonable request.

\section{Declarations}

\section{Ethics approval and consent to participate}

Ethical approval has been obtained for phase two through Ulster University Research Governance Filter Committee, Nursing and Health Research. Ethical approval for subsequent phases will be sought in a sequential manner. All study participants will provide written informed consent prior to data collection.

\section{Consent for publication}

Not applicable.

\section{Competing interests}

Authors declare no competing interests.

\author{
Author details \\ 'Institute of Nursing and Health Research, School of Nursing, Ulster \\ University, Shore Road, Newtownabbey BT37 0QB, Northern Ireland. \\ International Observatory on End of Life Care, Lancaster University, \\ Lancaster LA1 4YG, UK. ${ }^{3}$ Institute of Nursing and Health Research, Ulster \\ University, Shore Road Newtownabbey, Belfast, Co. Antrim BT37 OQB, \\ Northern Ireland. ${ }^{4}$ Marie Curie Hospice Belfast, 1a Kensington Road, Belfast \\ BT5 6NF, Northern Ireland.
}

\section{Received: 25 February 2021 Accepted: 16 March 2021} Published online: 08 April 2021

\section{References}

1. NHS Scotland. Percentage of end of life spent at home or in a community setting. Financial years ending 31st March 2011 to 2017. Information service division, publication report. NHS Scotland, Scotland, 2017.

2. Thomas K. The gold standards framework in community palliative care. Eur J Palliat Care. 2003;10:113-5.

3. Thomas K. Out-of-hours palliative care - bridging the gap. Eur J Palliat Care. 2000;7:22-5.

4. Shipman C, Addington-Hall J, Barclay S, Briggs J, Cox I, Daniels L, Millar D. Providing palliative care in primary care: how satisfied are GPs and district nurses with current out-of-hours arrangements? Br J Gen Pract. 2000; 50(455):477-8.

5. Williams H, Donaldson L, Noble S. Quality improvement priorities for safer out-of-hours palliative care: lessons from a mixed-methods analysis of a national incident reporting database. Pall Med. 2019;33(3):346-56. https:// doi.org/10.1177/0269216318817692.

6. Curie M. Palliative and end of life care Priority Setting Partnership. (PeolcPSP). UK: Marie Curie; 2015. https://www.mariecurie.org.uk/globala ssets/media/documents/research/PeolcPSP_Final_Report.pdf (cited 20th November 2019)
7. Brettell R, Fisher R, Hunt H, Garland S, Lasserson D, Hayward G. What proportion of patients at the end of life contact out-of-hours primary care? A data linkage study in Oxfordshire. BMJ Open. 2018;8:e 020244. https://doi. org/10.1136/bmjopen-2017-020244.

8. Fordman FT, McMillan S, Best S, Candy B, Thakrar S, Noble B. How current UK research addresses out of hours palliative care. BMJ Support Palliat. 2016; 6:384-408.

9. Sun Z, Laporte A, Guerriere DN, Coyte PC. Utilisation of home-based physician, nurse and personal support worker services within a palliative care programme in Ontario, Canada: trends over 2005-2015. Health Soc Care Commun. 2017;25(30):1127-38. https://doi.org/10.1111/hsc.12413.

10. Williams AM, Wang $L$, Kitchen P. Impacts of care-giving and sources of support: a comparison of end-of-life and non-end of- life caregivers in Canada. Health Soc Care Commun. 2016;24(2):214-24. https://doi.org/1 0.1111/hsc.12205.

11. Moriarty J, Manthorpe J, Gillian T, Cornes M, Hussein S. Social care practice with carers: What social care support is provided to family carers? What support do family carers want? Project Report. UK: National Institute for Health Research, School for Social Care Research: 2014. https://www. kcl. ac. uk/ sspp/policyinstitute/ scwru/ pubs/ 2014/ reports/ NIHR- SSCR- Research- Findings- Carers-Nov- 2014. Pdf (cited 15th November 2019)

12. Lovatt M, Nanton V, Roberts J, Ingleton C, Noble B, Pitt E, Seers K. Munday D. The provision of emotional labour by health care assistants caring for dying cancer patients in the community: a qualitative study into the experiences of health care assistants and bereaved family carers. Int J Nurs Stud 2015; 52(1): 271-279, DOl: https://doi.org/10.101 6/j.jinurstu.2014.10.013.

13. Aoun S, O'Connor M, Skett K, Deas K, Smith J. Do models of care designed for terminally ill 'home alone' people improve their end-of-life experience? A patient perspective. Health Soc Care Community. 2012;20(6):599-606. https://doi.org/10.1111/j.1365-2524.2012.01074.x.

14. Ingleton C, Chatwin J, Seymour J, Payne S. The role of health care assistants in supporting district nurses and family carers to deliver palliative care at home: findings from an evaluation project. J Clinic Nurs. 2011;20(13-14): 2043-52. https://doi.org/10.1111/j.1365-2702.2010.03563.x.

15. Herber $\mathrm{O}$, Johnston B. The role of healthcare support workers in providing palliative and end-of-life care in the community: a systematic literature review. Health Soc Care Community. 2013;21(3):225-35. https://doi.org/1 0.1111/j.1365-2524.2012.01092.x.

16. Devlin M, Mcllfatrick S. Providing palliative and end-of-life care in the community: the role of the homecare worker. Int J Palliat Nurs. 2010;16(4): 195-203. https://doi.org/10.12968/ijpn.2010.16.4.47786.

17. de Witt JB, Brazil K, Passmore P, Buchanan H, Maxwell D, Mcllfatrick S, Morgan SM, Watson M, Parsons C. Exploring healthcare assistants' role and experience in pain assessment and management for people with advanced dementia towards the end of life: a qualitative study. BMC Palliat Care. 2017; 16(6):1-11.

18. Morgan DG, Kosteniuk JG, O'Connell ME, Bello-Haas VD, Stewart NJ, Karunanayake C. Dementia-related work activities of home care nurses and aides: frequency, perceived competence, and continuing education priorities. Educ Gerontol. 2016;42(2):120-35. https://doi.org/10.1080/036012 77.2015.1083390.

19. Denham SA, Meyer MG, Rathburn A, Toborg MA. Thornton L. Knowledge of rural nurses' aides about end-of-life care. Fam Community Health 2006; 29: 229-241, 3, DOl: https://doi.org/10.1097/00003727-200607000-00010.

20. Lunn J, Sladek J, Holloway L. Ontario Personal support workers in home and community care: CRNCC/PSNI Survey Results. In: Focus; 2010. http:// www.ryerson.ca/content/dam/crncc/knowledge/infocus/factsheets/ InFocus-Ontario\%20PSWs\%20in\%20Home\%20and\%20Community\%20Care. pdf (cited 28th Nov 2019).

21. McDonnell M, McGuigan E, McElhinney J, McTeggart M, McClure D. An analysis of the palliative care education needs of RGNs and HCAs in nursing homes in Ireland. Int J Palliat Nurs. 2009:15(9):446,448-55.

22. Kelly S, Piercy H, Ibbotson R, Fowler-Davis S. Who attends out-of-hours general practice appointments? Analysis of a patient cohort accessing new out-of-hours units. BMJ Open. 2018;8(6):e020308. https://doi.org/10.1136/ bmjopen-2017-020308.

23. Magee C, Koffman J. Out of hours palliative care: what are the educational needs and preferences of general practitioners? BMJ Support Palliat Care. 2016;6(3):362-8. https://doi.org/10.1136/bmjspcare-2014-000764. 
24. Plummer S, Allan R. Analysis of a network-wide specialist palliative care outof-hours advice and support line: a model for the future. Int J Palliat Nurs. 2011;17(10):494-9.

25. Pesut B, McLean T, Reimer-Kirkham S, Hartrick-Doane G, Hutchings D, Russell LB. Educating registered nursing and health care assistant students in community-based supportive care of older adults: a mixed methods study. Nurs Educ Today. 2015;32(9):142-51.

26. Hasson F, McKenna H, Keeney S. A qualitative study exploring the impact of student nurses working part time as a health care assistant. Nurs Educ Today. 2019;33(8):873-9.

27. Creswell JW, Plano-Clark V. Designing and conducting mixed methods research. Thousand Oaks: Sage; 2011.

28. Patton MA. Qualitative Research \& Evaluation Methods. London: Sage; 2002.

29. Polit DF, Beck CT. Nursing research: principles and methods. Philadelphia: Lippincott Williams \& Wilkins; 2004.

30. Kaishik V, Walsh C. Pragmatism as a research paradigm and its implications for social work research. Soc Sci. 2019:8:255. https://doi.org/10.3390/ socsci8090255

31. Caracelli VJ, Greene JC. Data analysis strategies for mixed-method evaluation designs. EEPA. 1993;15(2):195-207.

32. Miles MB, Huberman AM. Qualitative data analysis. 2nd ed. Newbury Park: Sage; 1994.

33. Cronin A, Alexander V, Fielding J, Moran-Elis J, Thomas H. Chapter 34: the analytic integration qualitative data sources. In: Alasuutari P, Bickman L, Brannen J, editors. The Sage Handbook of Social Research Methods. London: Sage; 2008

34. Fee A, Muldrew D, Slater P, Payne S, Mcllfatrick S, McConnell T, Finlay D-A Hasson $F$. The roles, responsibilities and practices of healthcare assistants in out of hours community palliative care: a systematic scoping review. Pall Med. 2020:38(8):976-88.

35. Mays N, Roberts E, Popay J. Synthesizing research evidence. In: Fulop N, Allen P, Clarke A, Black N, editors. Studying the Organisation and Delivery of Health Services: Research methods. London: Routledge; 2001.

36. Arksey H, O'Malley L. Scoping studies: towards a methodological framework. Int J Soc Res. 2005;8(1):19-32.

37. Levac D, Colquhoun H, O'Brien KK. Scoping studies: advancing the methodology. Implement Sci. 2010;5:69. https:/doi.org/10.1186/1748-5908-5-69.

38. Sivo A, Saunders C, Chang Q, Jiang J. How low should you go? Low response rates and the validity of inference in IS questionnaire research. JAIS. 2006;7(6):351-414. https://doi.org/10.17705/1jais.00093.

39. Regmi PR, Waithaka E, Paudyal A, Simkhada P, van Teijlingen E. Guide to the design and application of online questionnaire surveys. Nepal J Epidemiol. 2016;6(4):640-4

40. Andrews D, Nonnecke B, Preece J. Electronic survey methodology: a case study in reaching hard to involve internet users. Int J Hum Comput Interact. 2003;16(2):185-210. https://doi.org/10.1207/S15327590IJHC1602_04.

41. Eysenbach G. Improving the quality of web surveys: the checklist for reporting results of internet e-surveys (CHERRIES). J Med Internet Res. 2004; 6(3):e34. https://doi.org/10.2196/jmir.6.3.e34.

42. Payne S. Mixed methods approaches organisational case study methodology. England: University of Sheffield, Palliative and End of Life Group Research Group; 2002

43. Yin RK. Case study research: design and methods. UK: Sage; 2003.

44. Payne S, Field D, Rolls L, Hawker S, Kerr C. Case study methods in end of life care: reflections on the three studies. J Ad Nurs. 2007:58(3):236-45.

45. Oliver P, Jupp V. Purposive sampling. In: Alasuutari P, Bickman L, Brannen J. The Sage Handbook of Social Research Methods. London: Sage, 2008.

46. Mason M. Sample size and saturation in PhD studies using qualitative interviews. Forum Qual Soc Res. 2010;11(3). https://doi.org/10.17169/ fqs-11.3.1428.

47. Ritchie J, Spencer L. Qualitative data analysis for applied policy research. In: Burgess RG BA, editor. Analyzing Qualitative Data. London: Routledge; 1994. Qualitative data analysis for applied policy research.

48. Krueger RA, Casey MA, Focus Groups. A Practical Guide for Applied Research. CA: SAGE publications; 2015.

49. Morgan DL, Ataie J, Carder P, Hoffman K. Introducing dyadic interviews as a method for collecting qualitative data. Qual Health Res. 2013;23(9):1276-84. https://doi.org/10.1177/1049732313501889.

50. Greenbaum, T. Internet focus groups are not focus groups-So don't call them that. (2008) Retrieved from http://www.groupsplus.com/pages/ qmrr0798.htmGoogle Scholar
51. Woodyatt CR, Finneran CA, Stephenson R. In-person versus online focus group discussions: a comparative analysis of data quality. Qual Health Res. 2016;26(6):741-9. https://doi.org/10.1177/1049732316631510.

52. Kite, J., Phongsavan, P. Insights for conducting real-time focus groups online using a web conferencing service. (2017) F1000Research, 6.

53. Daniels N, Gillen P, Casson K, Wilson I. STEER: factors to consider when designing online focus groups using Audiovisual Technology in Health Research. Int J Qual Methods. 2019;18:160940691988578. https://doi.org/1 $0.1177 / 1609406919885786$.

54. Braun V, Clarke V. Using thematic analysis in psychology. Qual Res Psychol. 2006:3(2):77-101. https://doi.org/10.1191/1478088706qp063oa.

55. Data Protection Act 2018, c. 12, Europe: European Union http://www.legisla tion.gov.uk/ukpga/2018/12/contents/enacted (cited 20th Dec 2019.

56. Guerin S, Kernohan WG. Developing and exploring a model of knowledge transfer and exchange for use in palliative care settings. Ireland: AllHPC Work Package 8; 2017. http://www.professionalpalliativehub.com/sites/defa ult/files/EMTReK\%20Model_Workshop_Slides.pdf (Cited 24 ${ }^{\text {th }}$ February 2019)

\section{Publisher's Note}

Springer Nature remains neutral with regard to jurisdictional claims in published maps and institutional affiliations.
Ready to submit your research? Choose BMC and benefit from:

- fast, convenient online submission

- thorough peer review by experienced researchers in your field

- rapid publication on acceptance

- support for research data, including large and complex data types

- gold Open Access which fosters wider collaboration and increased citations

- maximum visibility for your research: over $100 \mathrm{M}$ website views per year

At BMC, research is always in progress.

Learn more biomedcentral.com/submissions 